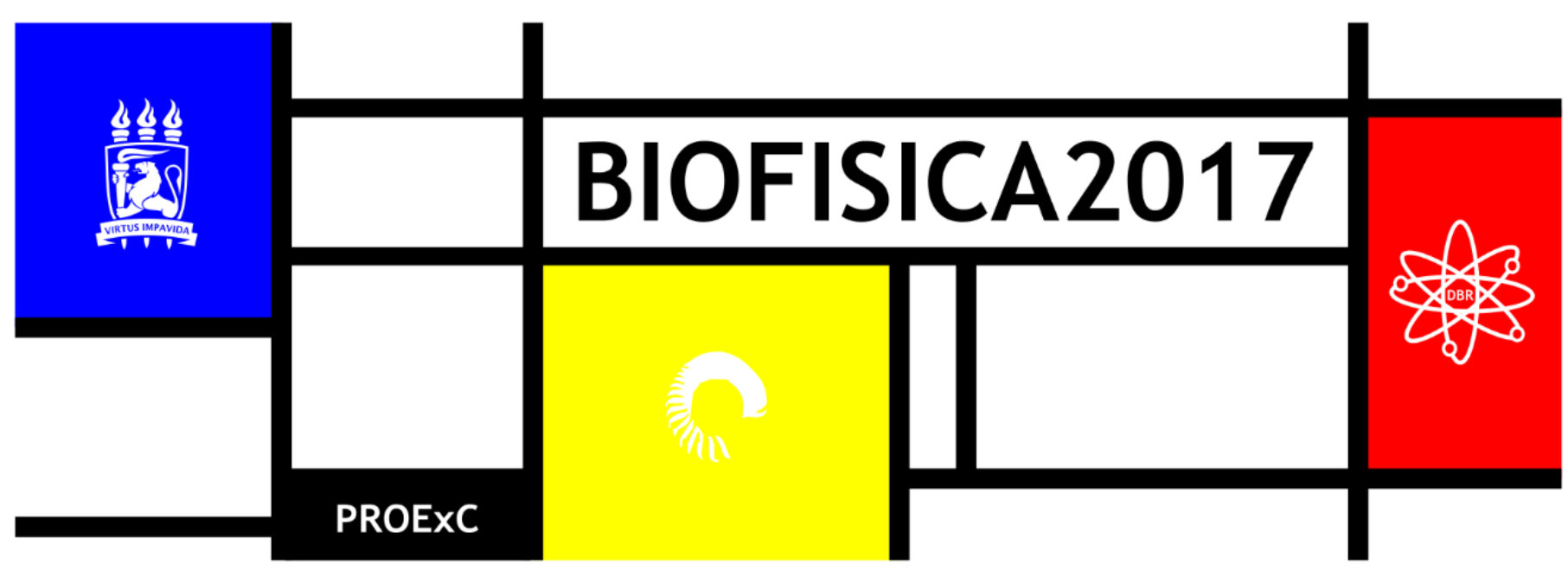

\title{
EFEITOS MUTAGÊNICOS EM HEMÓCITOS DE CARAMUJOS LITTORARIA ANGULIFERA DE MANGUEZAL URBANO
}

\author{
Katarine Mizan ${ }^{1,2 *}$, Danielly Silva², Fabiano Oliveira Junior², Rebeca Cantinha ${ }^{2}$, Ana Melo ${ }^{2}$ Elvis França² \\ ${ }^{1}$ Laboratório de Radiobiologia e Biofísica - UFPE; ${ }^{2}$ Centro Regional de Ciências Nucleares do Nordeste - CRCN-NE; ${ }^{3}$ Laboratório de Citologia - \\ UFPE \\ *katarine.mizanl@gmail.com.br
}

\section{INTRODUÇÃO}

Os manguezais são resultados de fatores bióticos e abióticos com um microclima específico para a ocorrência de flora e fauna, na maior parte endêmica. Devido a essa condição ambiental, esse tipo vegetacional é considerado um berçário para diversas espécies de aves e peixes (SCHAEFFER-NOVELLI, 1995).

A proximidade de zonas urbanas, principalmente, regiões metropolitanas, é um dos fatores responsáveis por algumas drásticas mudanças nos organismos que ali estão presentes (BRANDÃO et al., 2009). Essas intensivas interferências geram pressões antrópicas que podem resultar em mutagenicidade.

Em razão da ausência de informações na literatura sobre a resposta dessa pressão antrópica em nível genético em caramujos de manguezais urbanos em Pernambuco, este estudo aplicou o teste do micronúcleo para analisar os hemócitos do gastrópode Littoraria angulifera do Manguezal Chico Science, no Espaço Ciência, em Pernambuco.

\section{MATERIAL E MÉTODOS}

Os indivíduos foram coletados no manguezal Chico Science do Espaço Ciência e encaminhados para o Laboratório de Radiobiologia e Biofísica, do Departamento de Biofísica no Centro de Biociências (CB) da Universidade Federal de Pernambuco (UFPE). A limpeza dos espécimes foi realizada com água corrente e solução de detergente Extran 1\%. A hemolinfa foi extraída por punção da região denominada Sinus bucal, localizada na região anterior da cabeça (Figura 1).

A metodologia para extração da hemolinfa foi otimizada a partir dos protocolos convencionais desenvolvidos para gastrópodes. A hemolinfa extraída foi depositada diretamente na lâmina de microscopia, contendo EDTA. Os hemócitos depositados na lâmina de microscopia com EDTA foram mantidos em câmara escura por 30 minutos. Após esse intervalo, as lâminas seguiram para a etapa de fixação com gluteraldeído por $10 \mathrm{~min}$ e o excesso de reagentes e hemolinfa removido com água destilada. Os hemócitos após fixação foram corados com Giemsa a 10\% durante 7 minutos. As lâminas com os hemócitos corados, deixadas na vertical para secar em temperatura de fora $\left(25^{\circ} \mathrm{C}\right)$. Detalhes do procedimento podem ser consultados em Silva (2010).

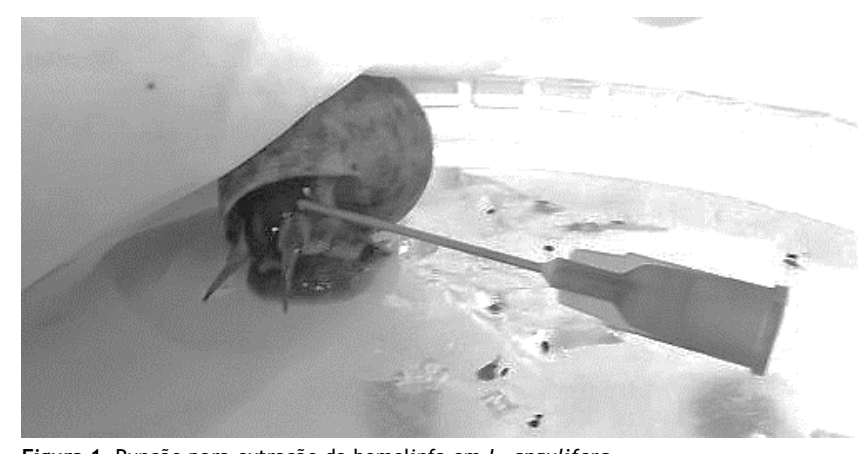

Figura 1. Punção para extração da hemolinfa em L. angulifera.

Figura 2. Hemócito de Littoraria angulifera contendo micronúcleo.

Para obtenção da frequência de micronúcleos um total de 4.000 hemócitos foram analisados em microscópio óptico com a objetivas de 100x, obtendo-se fotomicrografias com magnitude de 1000x. Foi utilizado o intervalo de confiança de Wald corrigido para a obtenção dos limites superiores e inferiores em nível de $95 \%$ de confiança (WILSON, 1927). 


\section{RESULTADOS E DISCUSSÃO}

0 teste do micronúcleo resultou na contagem total de 14 células com um micronúcleo, das 4.000 células contabilizadas (Figura 2). A frequência média de micronúcleos observada para $L$. angulifera nesse trabalho foi $0,35 \%$ e os intervalos de confiança de Wilson em nível de $95 \%$ de confiança variaram entre $021 \%$ e $0,58 \%$.

A Figura 3 mostra a comparação entre a frequência de micronúcleo do Littoraria angulifera desse estudo, e resultados de trabalhos com Ucydes cordatus e Biomphalaria glabrata.

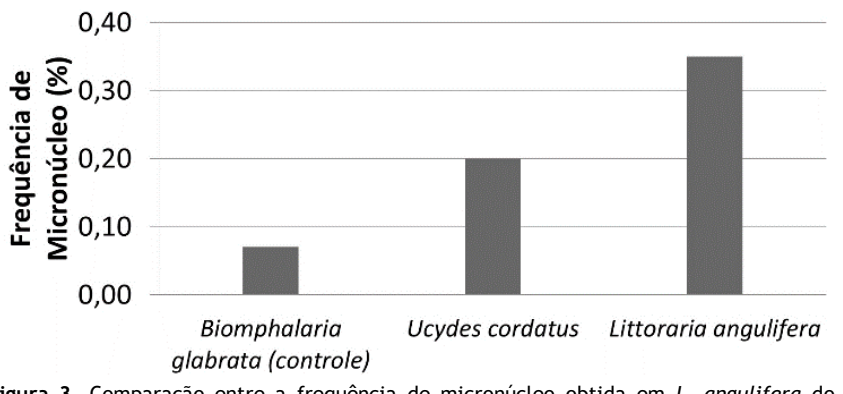

Figura 3. Comparacão entre a frequência de micronúcleo obtida em $L$. angulifera do Manguezal Chico Science e em espécies citadas na literatura

A frequência encontrada para a espécie estudada foi semelhante ao resultado de um estudo em um manguezal impactado do município de Cubatão, São Paulo, no crustáceo de manguezal Ucides cordatus, (frequência de micronúcleo de 0,20\%) (PINHEIRO et al., 2013). 0 resultado desse trabalho foi cinco vezes maior que o observado por Silva (2010) em estudo realizado com indivíduos de $B$. glabrata criados em laboratório $(0,07 \%)$.

\section{CONCLUSÃO}

A partir deste estudo, há indícios de que a pressão ambiental sofrida pelos animais em manguezais urbanos impactados esteja induzindo mutagenicidade na espécie estudada.

\section{REFERÊNCIAS}

BRANDÃO, I.M.; GUIMARÃES, A.S.; TRAVASSOS, P.E.P. Ecologia de paisagem: uma análise multi-temporal dos manguezais urbanos do complexo de salgadinho, Olinda-PE. Anais... XIV Simpósio Brasileiro de Sensoriamento Remoto, Natal, Brasil, INPE, p.25-30. 2009.

PINHEIRO, M. A. A.; DUARTE, L. F. A.; TOLEDO, T.R. ADAM, M. L.; TORRES, R. A. Habitat monitoring and genotoxicity in Ucides cordatus (Crustacea: Unicididae), as tools to manage a mangrove reserve in southeastern Brazil. Environmental Monitoring and Assessment, v.185, p.8273-8285, 2013.

SHAEFER-NOVELLI, Y. Manguezal: Ecossistema entre a terra e o mar. $1^{\circ}$ ed. São Paulo: Caribbean Ecological Research, 64p. 1995.

SILVA, A. S. C. Padrões de distribuição em litorínideos (Mollusca: Gastropoda) da Costa Brasileira. Tese (Doutorado em Genética e Biologia Molecular na área de Genética Animal e Evolução) - Instituto de Biologia, Universidade Estadual de Campinas, 2005. Disponível em:

<http://www.bibliotecadigital.unicamp.br/document/?code=vtls00 0365930>. Acesso em 23/04/2015.

WILSON, E. B. Probable inference, the law of sucession, and statistical inference, Journal of the American Statistical Association, v. 22, p.209-212. 1927. 